\title{
Sinomenine induces the generation of intestinal Treg cells and attenuates arthritis via activation of aryl hydrocarbon receptor
}

\author{
Bei Tong ${ }^{1,2}$, Xusheng Yuan', Yannong Dou', Xin Wu' ${ }^{1}$, Yuhui Wang ${ }^{1}$, Yufeng Xia ${ }^{1}$ and Yue Dai ${ }^{1}$
}

Sinomenine (SIN), an anti-arthritis drug, has previously been proven to exert immunomodulatory activity in rats by inducing intestinal regulatory T-cells (Treg cells). Here, we assessed the effect of SIN on the generation and function of Treg cells in autoimmune arthritis, and the underlying mechanisms in view of aryl hydrocarbon receptor (AhR). The proportions of Treg cells and IL-17-producing T-cells (Th17 cells) differentiated from naive T-cells were analyzed by flow cytometric analysis. The AhR agonistic effect of SIN was tested by analyzing the activation of downstream signaling pathways and target genes. The dependence of intestinal Treg cell induction and arthritis alleviation by SIN on AhR activation was confirmed in a mouse collagen-induced arthritis $(\mathrm{CIA})$ model. SIN promoted the differentiation and function of intestinal Treg cells in vitro. It induced the expression and activity of $A h R$ target gene, promoted AhR/Hsp90 dissociation and $A h R$ nuclear translocation, induced XRE reporter activity, and facilitated AhR/XRE binding in vitro, displaying the potential to be an agonist of $A h R$. In CIA mice, SIN induced the generation of intestinal Treg cells, and facilitated the immunosuppressive function of these Treg cells as shown by an adoptive transfer test. In addition, the induction of intestinal Treg cells and the anti-arthritic effect of SIN in CIA mice could be largely diminished by the AhR antagonist resveratrol. SIN attenuates arthritis by promoting the generation and function of Treg cells in an AhR-dependent manner. Laboratory Investigation (2016) 96, 1076-1086; doi:10.1038/labinvest.2016.86; published online 12 September 2016

Sinomenine (SIN) is an isoquinoline alkaloid constituent occurring in Sinomenium acutum Rehd. et Wils. and other medicinal plants. An increasing number of preclinical and clinical studies demonstrate that oral sinomenine is effective against rheumatoid arthritis. ${ }^{1}$ Recently, our group reported that SIN functions by restoring systemic IL-17-producing T-cells (Th17)/regulatory T-cells (Treg) balance by inducing the generation of intestinal Treg cells and the migration of these cells to inflamed joint and synovium. ${ }^{2}$ This unique gut-dependent action mode of SIN led us to explore its immunomodulatory action and mechanism in more detail.

Aryl hydrocarbon receptor $(A h R)$, a ligand-dependent transcription factor, is famous for mediating the biotransformation and carcinogenic/teratogenic effects of environmental toxins (eg, TCDD, a prototypical xenobiotic ligand of $A h R$ ). With the cloning of $A h R$ gene in the early $1990 \mathrm{~s},{ }^{3}$ our understandings of the function of $A h R$ increased, but we are still lacking of studies in toxicology and pharmacology. ${ }^{4}$
Recently, the perspective on $A h R$ changed. It is now known that $A h R$ exerts an important regulatory effect on the development and function of both innate and adaptive immune cells when it responds to endogenous ligands generated from the host cells, the diet, and from microbiota, ${ }^{5-7}$ and it connects outside environmental signals to inside cellular processes with consequences for immune cell function. ${ }^{8}$

$A h R$ is mainly expressed in barrier tissues (eg, gut, skin, and lung) by immune cells such as lymphocytes. The gut is enriched with metabolites derived from either the diet or microflora, and some of these metabolites can function as $A h R$ ligands, binding to $A h R$ and consequently inducing its nuclear translocation and transcriptional activation. The gut also has a cytokine mileau resulting from cytokine production by immune cells such as dendritic cells, likely in response to gut microbiota. ${ }^{9}$ These environmental cues instruct the differentiation programs of immune cells (such as innate lymphoid cells and $\mathrm{T}$ cells), promoting the secretion and function of cytokines.

${ }^{1}$ Department of Pharmacology of Chinese Materia Medica, China Pharmaceutical University, Nanjing, China and ${ }^{2}$ Institute of Botany, Jiangsu Province and Chinese Academy of Science (Nanjing Botanical Garden Mem. Sun Yat-Sen), Nanjing, Jiangsu, China

Correspondence: Professor Y Dai or Professor Y Xia, Department of Pharmacology of Chinese Materia Medica, China Pharmaceutical University, 24 Tong Jia Xiang, Nanjing 210009, China.

E-mail: yuedaicpu@hotmail.com or yfxiacpu@126.com

Received 8 June 2016; revised 30 June 2016; accepted 30 June 2016 
Previous studies of our research group demonstrated that norisoboldine and tetrandrine, two members of the isoquinoline alkaloid family, attenuated collagen-induced arthritis through the activation of $A h R$, which suggested a potential relationship between SIN and $A h R \cdot{ }^{10,11}$ The present study was performed to clarify the effect of SIN on the activation of $A h R$, and its relevance to the induction of the generation and function of intestinal Treg cells and the consequent alleviation of arthritis.

\section{MATERIALS AND METHODS}

\section{Animals}

Specific pathogen-free, eight-week-old male DBA/1J mice were purchased from B\&K Universal Group Limited (Shanghai, China). They were maintained at a constant temperature and humidity, with a $12 \mathrm{~h}$ light-dark cycle. Water and a nutritionally adequate diet were provided ad libitum. All mice were observed daily for general health and clinical signs of disease. At the end of the study, mice were killed by $\mathrm{CO}_{2}$ asphyxiation, followed by exsanguination, and tissues were collected postmortem. Animal welfare and experimental procedures were carried out in strict accordance with the Guide for the Care and Use of Laboratory Animals (National Institutes of Health) and the related ethical regulations of China Pharmaceutical University.

\section{Reagents}

SIN (purity $>98 \%$, Supplementary Figure 1) was purchased from Nanjing Zelang Pharmaceutical Technology (Nanjing, China). Leflunomide (LEF) was purchased from Suzhou Changzheng Xinkai Pharmaceutical (Suzhou, China); 2,3,7,8tetrachlorodibenzo- $p$-dioxin (TCDD) was purchased from AccuStandard (New Haven, CT, USA); actinomycin D (Act-D) was purchased from Zhejiang Hisun Pharmaceutical (Hangzhou, China). TGF- $\beta$, IL-6, IL-2, anti-CD3/CD28 were purchased from BD Biosciences (Franklin Lakes, NJ, USA). Complete Freund's adjuvant (CFA), incomplete Freund's adjuvant (IFA), chicken type II collagen (CII), $\alpha$-naphthoflavone $(\alpha-\mathrm{NF})$, resveratrol (RES), and cycloheximide (CHX) were purchased from Sigma-Aldrich (St Louis, MO, USA). RPMI-1640 medium, trypsin, penicillin, and streptomycin were purchased from Gibco BRL (Grand Island, NY, USA). Newborn calf serum (NCS) was purchased from PAA Laboratories $\mathrm{GmbH}$ (Morningside, Australia). The $\mathrm{CD}^{+}$ $\mathrm{CD} 2 \mathrm{~L}^{+} \mathrm{T}$ cell isolation Kit II was purchased from Miltenyi Biotec (Headquarters, Germany). FITC-anti-CD4, APC-antiCD25, PE-anti-Foxp3, APC-anti-IL-17A, PE-anti-IFN- $\gamma$, Annexin V, 7-AAD, fixation/permeabilization concentrate, and diluent solutions were purchased from eBioscience (San Diego, CA, USA). PMA/Ionomycin mixture and BFA/Monensin mixture were purchased from MultiSciences Biotech (Hangzhou, China). RNAi sequences directed against the mouse $A h R$ gene were designed and chemically synthesized by RiboBio (Guangzhou, China). Mouse IL- $1 \beta$, TNF- $\alpha$, IL-6, IFN- $\gamma$, IL-4, IL-10, and IL-17A ELISA kits were purchased from Dakewe Biotech (Shenzhen, China); mouse anti-CII antibodies (IgG, IgG1, and IgG2a) were purchased from GENMED SCENTIFICS (Wilmington, USA). TRIzol reagent was purchased from Invitrogen (Carlsbad, CA, USA). HiScript Q RT SuperMix and AceQ qPCR SYBR Green Master Mix were purchased from Vazyme Biotech (Piscataway, NJ, USA). Antibodies for CYP1A1 and AhR were purchased from Santa Cruz Biotechnology (Santa Cruz, CA, USA). The other chemicals and reagents used were of analytical grade.

\section{T-Helper Cell Isolation, Sorting, and Differentiation}

Naive T-cells were purified from mesenteric lymph nodes (MLNs) of DBA1/J mice, by magnetically sorting live $\left(\mathrm{DAPI}^{-}\right), \mathrm{CD}^{+} \mathrm{CD}^{-} \mathrm{L}^{+}$naive $\mathrm{T}$-cells using a $\mathrm{CD} 4^{+} \mathrm{CD} 2 \mathrm{~L}^{+}$ $\mathrm{T}$ cell isolation Kit II (Miltenyi Biotec, Germany) according to the manufacturer's instructions. Naive T-cells were activated with anti-CD3 $(5 \mu \mathrm{g} / \mathrm{ml})$ and anti-CD28 $(1 \mu \mathrm{g} / \mathrm{ml})$. Cells were cultured for 4-5 days under Th17 differentiation conditions (TGF- $\beta 1,5 \mathrm{ng} / \mathrm{ml}$; IL-6, $20 \mathrm{ng} / \mathrm{ml}$ ) or under Treg differentiation conditions (TGF- $\beta 1,5 \mathrm{ng} / \mathrm{ml}$ ) in the presence or absence of $\operatorname{SIN}(0.1,0.3,1 \mathrm{mM}) .^{10}$

\section{Flow Cytometry}

Single cell suspensions were stimulated with PMA, ionomycin, and GolgiStop for $4 \mathrm{~h}$ at $37^{\circ} \mathrm{C}$. Cells were stained with anti-CD4 antibody, permeabilized with $0.1 \%$ Triton, and stained with anti-IFN $\gamma$ or anti-IL-17 antibodies. To detect Treg, single-cell suspensions were stained with anti-CD4 and anti-CD25 antibodies, fixed, permeabilized, and stained with anti-Foxp3 antibody. Isotype controls were included in all experiments to adjust the background signal.

For the analysis of cell apoptosis, cells were stained with Annexin $\mathrm{V}$ and 7-AAD, and loaded on the flow cytometer. ${ }^{12}$ Flow cytometric analysis was performed in a FACSCalibur instrument and analyzed with FlowJo software.

\section{Suppression Assay}

$\mathrm{CD} 4{ }^{+} \mathrm{CD} 25^{+}$Treg cells were sorted from the naive T-cells, which were stimulated under Treg differentiation conditions with or without SIN (1 mM) for 6 days (Treg-SIN and TregCtrl, respectively). Freshly isolated $\mathrm{CD} 4{ }^{+} \mathrm{CD} 25^{-}$T-cells (Teff cells) were co-cultured with Treg-SIN or Treg-Ctrl cells at the indicated ratio $(1: 0,10: 1,10: 3,1: 1)$ for 3 days. The results were analyzed by CFSE cell proliferation assay using a flow cytometry.

\section{Lymphocyte Culture and Treatments}

EL-4 cells (a mouse lymphoma cell line) were cultured in RPMI-1640 medium supplemented with 10\% FBS. For all the in vitro experiments, equal volumes of the appropriate solvent were added to the control group. For experiments involving Act-D, $\alpha$-NF, RES, and CHX, the first three chemicals were added $2 \mathrm{~h}$ before, whereas CHX was added $0.5 \mathrm{~h}$ before SIN (1 $\mathrm{mM})$ treatment. 


\section{Western Blot and Co-Immunoprecipitation Assay}

Western blot analysis was performed as previously described. ${ }^{10}$ All values were expressed relative to the expression of GAPDH.

For the co-immunoprecipitation assay, cultured cells were lysed in $25 \mathrm{mM}$ Tris ( $\mathrm{pH} 8.0$ ), $100 \mathrm{mM} \mathrm{NaCl}, 0.5 \% \mathrm{NP}-40$, $10 \mathrm{mM} \mathrm{MgCl}, 10 \%$ glycerol, $1 \times$ protease inhibitor and PhosphoSTOP on ice for $30 \mathrm{~min}$, followed by homogenization with a 25-gauge needle. Cell lysates were incubated with anti-Hsp90 antibody overnight at $4{ }^{\circ} \mathrm{C}$ for pull-down assays and then with $20 \mu \mathrm{l}$ Protein A/G Plus-Agarose for another $4 \mathrm{~h}$ at $4{ }^{\circ} \mathrm{C}$. After washing with PBST, proteins were immuneblotted with the appropriate antibodies.

\section{Quantitative Real-Time PCR (qPCR)}

For analysis of mRNA transcripts, gene specific values were normalized to the GAPDH housekeeping gene for each sample. ${ }^{13}$ The primer sequences used were: for Foxp3, 5'-GG CCCTTCTCCAGGACAGA-3' (sense) and 5'-GCTGATCAT GGCTGGGTTGT-3' (antisense); for ROR $\gamma t$, $5^{\prime}$-TGTCCTGG GCTACCCTACTG-3' (sense) and 5'-GTGCAGGAGTAGGC CACATT-3' (antisense); for IL-10, 5' -CAAGCACCACTCCA CCTAGC-3' (sense) and 5'-GAGAGAGACCAGTTGGCGA G-3' (antisense); for IL-17A, 5'-CCTCAAAGCTCAGCGTGT CC-3' (sense) and 5'-GAGCTCACTTTTGCGCCAAG-3' (antisense); for CYP1A1, 5'-GACCTGAATGAGAAGTTCTACAG C-3' (sense) and 5'-CGGAAGGTCTCCAGGATGAAG-3' (antisense); for GAPDH, 5'-TTCACCACCATGGAGAAGGC-3' (sense) and 5'-GGCATGGACTGTGGTCATGA-3' (antisense).

\section{Transfection}

RNAi sequences directed against the mouse $A h R$ gene were designed and chemically synthesized. We searched the genome database (BLAST, SSEARCH) to ensure that these sequences do not target other human genes. EL-4 cells were plated in culture plates and allowed to grow to $\sim 40 \%$ confluence. Transfections with siRNA were performed using lipofectamine 2000 reagent in six-well plates at $\sim 40 \%$ confluence. Three different siRNA for $A h R$ were used for getting the optimal transfection. EL-4 cells were transfected with these siAhRs, respectively. The knock-down efficiencies were assessed by PCR $48 \mathrm{~h}$ after transfection. SiAhR \#1 with the most optimal transfection efficiency was chosen for the subsequent experiments (Supplementary Figure 2).

\section{Assay of CYP1A1 Activity}

The CYP1A1-dependent ethoxyresorufin-O-deethylase activity was assayed as previously described. ${ }^{10}$ Enzymatic activity was normalized for cellular protein content according to the manufacturer's instructions.

\section{Luciferase (Luc) Assay}

Lymphocytes were transiently transfected with the XREluciferase reporter plasmid pGL3-control, pGL3basic, and pGL3-XRE-Y by incubating cells with DNA-Lipofectamine
2000 complexes. $^{10}$ After transfection, cells were incubated with indicated treatments and then lysed. The lysates were assayed for luciferase activity using the luciferase assay system (Promega, Madison, WI, USA) with a luminometer according to the manufacturer's instructions. Luciferase activities were reported as emitted light per well as a percent of normal group.

\section{Electrophoretic Mobility Shift Assay (EMSA)}

Nuclear extracts from lymphocytes were prepared using a nucleoprotein extraction kit. A complementary pair of synthetic oligonucleotides containing the XRE binding site for the transformed AhR/Arnt complex (5'-GATCTGGCTC TTCTCACGCAACTCCG-3' and 5'-GATCCGGAGTTGCGT GAGAAGAGCCA-3') were synthesized, purified, and labeled with biotin. The nuclear extracts mixed with probe were incubated with $2 \mu \mathrm{g}$ of poly ( $\mathrm{dI} / \mathrm{dC}$ ) acid in binding buffer for $30 \mathrm{~min}$ at $4{ }^{\circ} \mathrm{C}$, resolved on a $6.5 \%$ polyacrylamide gel at $100 \mathrm{~V}$ for $1 \mathrm{~h}$, and then transferred to a nylon membrane. For supershift assays, the nuclear extracts were incubated with $A h R$ antibodies for $30 \mathrm{~min}$ at $37^{\circ} \mathrm{C}$ before the complexes were analyzed by EMSA. The immunoreactive bands on nylon membranes were visualized by film exposure with enhanced chemiluminescence detection reagents. ${ }^{14,15}$

\section{$\mathrm{CIA}$ Induction and Treatment}

Experimental arthritis was induced according to the methodology described previously. ${ }^{10}$ Ten-week-old male mice were immunized by intradermal injection at the base of the tail with $100 \mathrm{mg}$ type II collagen (CII) in CFA on day 0 , and a boosting injection of $100 \mathrm{mg}$ CII dissolved in IFA on day 21 . Animals were daily inspected and the number of arthritic limbs per mouse was registered. Arthritis was defined as a visible joint erythema and/or swelling of at least one joint. The clinical severity of arthritis was graded daily for each paw by two independent observers using the following scoring system: 0 point $=$ normal; 1 point $=$ slight erythema; 2 points $=$ slight swelling plus erythema; 3 points $=$ moderate swelling and erythema; 4 point =edema and erythema from the ankle to the entire leg, yielding a maximum score of 16 per mouse. Disease severity was expressed as the mean arthritis index \pm s.e.m. per group of treatment.

For treatments, SIN was administered intragastrically (i.g.) at $120 \mathrm{mg} / \mathrm{kg} / \mathrm{day}$, LEF was administered i.g. at $2 \mathrm{mg} / \mathrm{kg} / \mathrm{day}$, and RES was administered i.g. at $20 \mathrm{mg} / \mathrm{kg} /$ day.

\section{Adoptive Transfer Experiment}

On day 41 after collagen immunization, $\mathrm{CD}^{+} \mathrm{CD} 25^{+} \mathrm{T}$-cells were sorted from mouse MLNs treated with SIN (SIN-Treg) or vehicle (Model-Treg) using a magnetic bead sorting system. Thereafter, $3 \times 10^{6}$ cells were adoptively transferred into recipient mice three times after the first immunization. ${ }^{16}$ After arthritic symptoms appeared, the arthritis index was observed and recorded for another two weeks. 


\section{Measurement of Cytokines and Anti-CII Antibodies}

Serum was collected from mice with CIA and levels of cytokines (IL- $1 \beta$, TNF- $\alpha$, IL- 6 , IFN- $\gamma$, IL-4, IL-10, and IL-17A) and anti-CII antibodies (IgG, IgG1, and IgG2a) were measured using mouse ELISA kits according to the manufacturer's instructions. A standard curve was generated for each assay by including serial dilutions of a reference sample of pooled sera from arthritic mice. Relative level of cytokines and antibody units (AU) were obtained for each sample by reference to the standard curve.

\section{Histological Assessment of Joint Inflammation and Cartilage Damage}

Paws were removed and fixed overnight in 4\% formaldehyde, decalcified with immunocal and embedded in paraffin. Sections $(5 \mu \mathrm{m})$ were prepared and stained with hematoxylin-eosin for assessment of inflammation and histological damage. The sections were evaluated in relation to the presence of inflammatory infiltrates, synovial membrane hyperplasia, pannus formation, cartilage destruction, and bone erosion.

\section{Immunostaining}

Cell immunostaining was performed as previously described with minor modifications. ${ }^{17}$ Cells were incubated with anti$A h R$ antibody overnight at $4{ }^{\circ} \mathrm{C}$, and then incubated with a secondary antibody conjugated with Rhodamine B for $2 \mathrm{~h}$. They were then incubated with DAPI. The images were obtained under a fluorescence microscope. Confocal microscopy of immunostaining was performed as previously described with a slight modification. ${ }^{18}$ The tissues were fixed in acetone and stained using antibodies of anti-CD4, antiCD25, and anti-Foxp3 for Treg cells. For the staining of Th17 cells, anti-CD4, and anti-IL-17 antibodies were used.

\section{Molecular Docking}

The three-dimensional structure of $A h R$ was downloaded from the protein database (protein data bank, PDB), serial number: IP97. SIN was inserted into the active site of the structure, and the binding ability was detected.

\section{Statistical Analysis}

Data are presented as the means \pm s.e.m. of three independent experiments. Comparisons between multiple groups were performed using the one-way analysis of variance and the Dunnett's test. Values of $P<0.05$ were considered to be statistically significant.

\section{RESULTS}

SIN Induced the Generation and Activation of Treg Cells Naive $\mathrm{CD}^{+} \mathrm{CD} 2 \mathrm{~L}^{+}$T-cells, isolated from the MLNs of DBA1/J mice, were activated under Treg differentiation condition in the presence or absence of SIN. SIN markedly promoted the frequency of Treg cells (Figures $1 \mathrm{a}$ and b) and up-regulated the expressions of Foxp3 and $I L-10$, which were positively related to the activation extent of Treg cell (Figures $1 \mathrm{c}$ and $\mathrm{d}$ ).

$\mathrm{CD} 4{ }^{+} \mathrm{CD} 25^{+} \mathrm{T}$-cells were sorted and co-cultured with Teff cells (CD $4^{+} \mathrm{CD} 25^{-} \mathrm{T}$-cells) to characterize the immunosuppressive activity of the Treg cells. Compared with the control Treg cells (Treg-Ctrl), Treg cells treated with SIN (Treg-SIN) showed a more potent ability to suppress the proliferation of Teff cells (Figure 1e). Then, co-cultured Teff cells were stained with Annexin $\mathrm{V}$ and 7-AAD to explore the mechanism of proliferation suppression of SIN. Co-incubation of Teff cells with SIN-treated T-cells showed an increased frequency of Annexin $\mathrm{V}^{+} 7-\mathrm{AAD}^{-}$(early apoptotic) cells and Annexin $\mathrm{V}^{+} 7-\mathrm{AAD}^{+}$(late apoptotic and/or dead) cells (Figures $1 \mathrm{f}-\mathrm{h}$ ), which meant that SIN-treated Treg cells could trigger apoptosis of the co-cultured Teff cells. Moreover, the differentiation of co-cultured Teff cells to IFN- $\gamma^{+}$T-cells (Th1) or IL-17 ${ }^{+}$T-cells (Th17) was analyzed by flow cytometry. The results suggested that SIN-treated Treg cells limited the differentiation of Teff cells to Th1 and Th17 cells (Figures $1 \mathrm{i}$ and j).

\section{SIN Restrained the Differentiation of Th17 cells}

Naive $\mathrm{CD} 4{ }^{+} \mathrm{CD}_{62} \mathrm{~L}^{+} \mathrm{T}$-cells were isolated and activated under Th17 differentiation condition in the presence or absence of SIN, and the proportions of $\mathrm{IL}-17^{+}$cells in $\mathrm{CD} 4^{+}$cells were analyzed by flow cytometry. The frequency of Th17 cells was markedly decreased from 12.5 to $7.88 \%$ after SIN (1 mM) treatment (Figures 2a and b). SIN (1 mM) inhibited the expression of $R O R \gamma t$ with an inhibitory ratio of $49.6 \%$ (Figure 2c). Furthermore, SIN (1 mM) markedly decreased the levels of $I L-17 A, I L-17 F$ and $I L-21$ in the supernatants (Figures 2d-f).

\section{SIN Induced the Expression of CYP1A1 in Lymphocytes Dependent on AhR}

Increasing evidence indicate the involvement of $A h R$ in the differentiation and activity of Treg cells. ${ }^{19-21}$ To examine whether $A h R$ participates in the induction of SIN on Treg cells, the potential cytotoxicity of SIN in EL-4 cells was tested and the optimal concentrations $(0.1,0.3$, and $1 \mathrm{mM})$ were used in the following studies, whereas TCDD was used as a positive control. SIN induced the expression of CYP1A1 (target gene of $A h R$ ) at protein and mRNA levels in a concentration-dependent manner, and it also markedly promoted the CYP1A1 activity (Figures $3 \mathrm{a}-\mathrm{c}$ ).

To identify whether the increased CYP1A1 expression in response to SIN was a result of de novo RNA synthesis or de novo protein synthesis, EL-4 cells were pre-incubated with RNA polymerase inhibitor (Act-D) and protein synthesis inhibitor (CHX), respectively. Both Act-D and $\mathrm{CHX}$ almost completely abolished the SIN-induced increase of CYP1A1 expression (Figures 3d-f), suggesting the requirement of $A h R$ for de novo RNA synthesis and protein synthesis in EL-4 cells. A siAhR transfection assay further confirmed the important role that $A h R$ had in SIN-induced CYP1A1 expression at protein and mRNA levels, and CYP1A1 activity (Figures $3 \mathrm{~g}-\mathrm{i}$ ). 
a

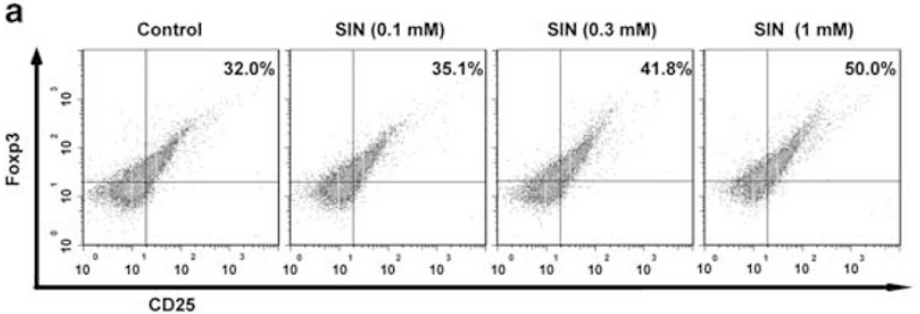

b

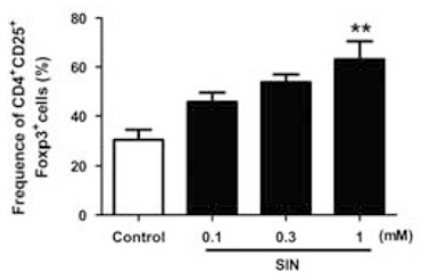

d

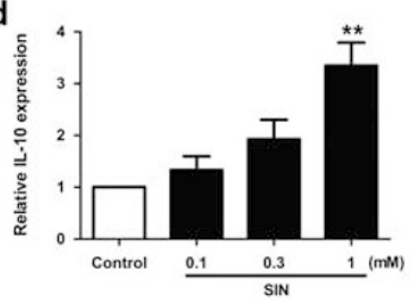

c

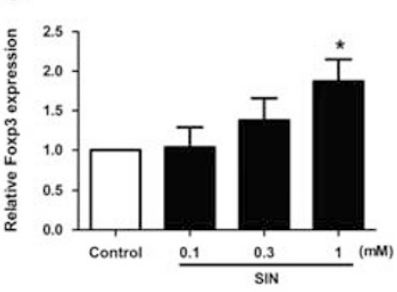

e

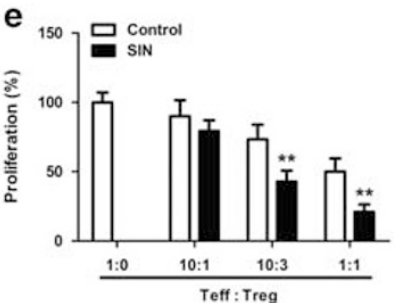

f

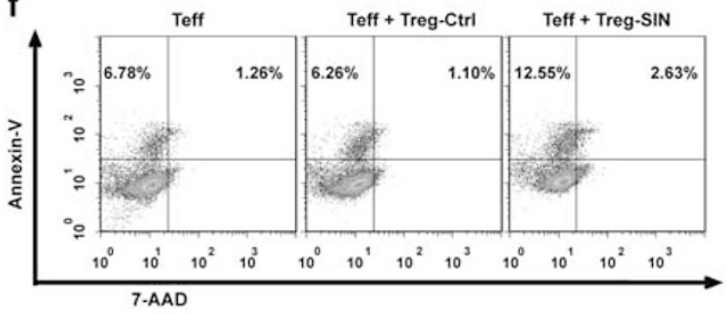

g

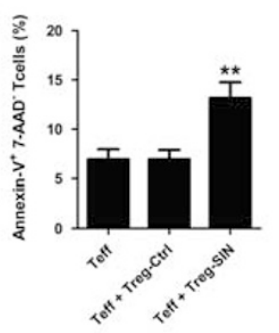

h

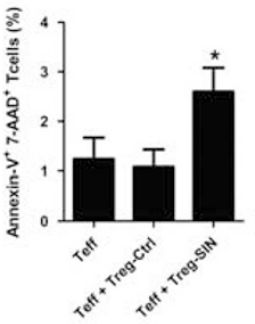

i

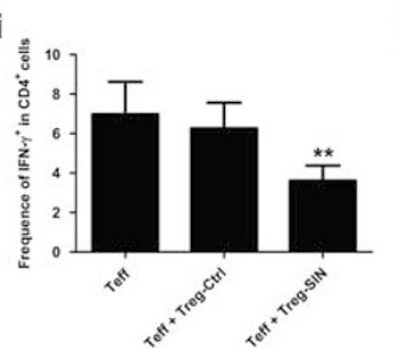

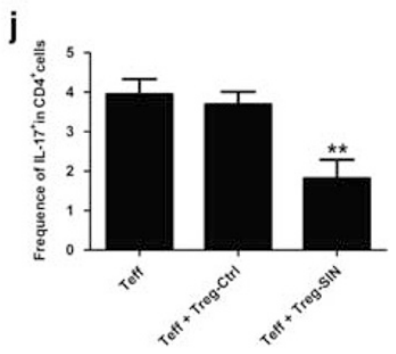

Figure 1 Sinomenine (SIN) promoted Treg cell differentiation in vitro. (a,b) Frequency of $\mathrm{CD} 4^{+} \mathrm{CD} 25^{+} \mathrm{Foxp} 3^{+}$cells was analyzed by flow cytometry. (c,d) Expressions of Foxp3 and IL-10 mRNA were analyzed by qPCR. (e) Suppressive effects of CD4 $4^{+} \mathrm{CD} 25^{+} \mathrm{T}$-cells, differentiated from naive T-cells in the presence or absence of SIN (1 mM) (Treg-SIN or Treg-Ctrl), on CD4 ${ }^{+} \mathrm{CD} 25^{-}$T-cells (Teff) were examined. Teff cells were co-incubated with Treg-Ctrl or Treg-SIN at the indicated ratio (1:0, 10:1, 10:3, 1:1) for 3 days. The proliferation of Teff cells was analyzed by flow cytometry. (f-h) Frequencies of Annexin $\mathrm{V}^{+}$7-AAD $\mathrm{T}$ and Annexin $\mathrm{V}^{+}$7-AAD ${ }^{+}$T-cells were counted in Teff cells co-incubated with Treg-SIN or Treg-Ctrl by flow cytometry.

(i,j) Frequencies of $\mathrm{CD}^{+} \mathrm{IFN}-\gamma^{+}$and $\mathrm{CD} 4^{+} \mathrm{IL}-17^{+} \mathrm{T}$-cells were counted in Teff cells co-incubated with Treg-SIN or Treg-Ctrl by flow cytometry. Experiments were conducted three times, and data were expressed as means \pm s.e.m., $n=3 .{ }^{*} P<0.05,{ }^{* *} P<0.01$ vs control. qPCR, quantitative real-time $P C R$.

\section{SIN Acted As an AhR Ligand}

We used a computer program that predicts docking targets of small molecular compounds and proteins to assess the potential association of SIN to $A h R$. SIN accessed to the active site, and appeared to bind to $A h R$ through van der Waals forces and the polarity effect.

The association of $A h R / H s p 90$ complex was analyzed by a co-immunoprecipitation test. SIN could effectively facilitate AhR/Hsp90 complex dissociation. RES, a known AhR antagonist, largely diminished the effect of SIN (Figure $4 \mathrm{~b}$ ). $A h R$ nuclear translocation was observed using fluorescence microscopy. Normally, $A h R$ protein was mainly localized in the cytoplasm of lymphocytes (control group). However, it was found almost exclusively in the nucleus after SIN or TCDD treatment (Figure 4c). To determine the effect of SIN on binding activation, we performed an XRE reporter assay. SIN markedly enhanced XRE reporter activity in EL-4 cells (Figure 4d). Ligand-dependent activation of the AhR/Arnt heterodimer to XRE can be monitored by incubation of nuclear proteins with the ligand in vitro, followed by EMSA.
Figure 4e showed that SIN effectively promoted the binding of AhR/Arnt to XRE sequence in CYP1A1 promoter.

\section{An AhR Antagonist Abolished the Regulatory Effect of SIN on Th17/Treg Balance in CIA Mice}

SIN was orally administered to CIA mice for two consecutive weeks from day 26 after the first immunization, and the CYP1A1 expression in the MLN tissues was evaluated. SIN markedly increased the protein level and mRNA expression of CYP1A1 in MLNs, and this inductive effect of SIN could be restored by RES treatment (Figure 5a).

The frequencies of Th17 and Treg cells in the intestine tissues of CIA mice were monitored by the flow cytometry (Figures 5b-e) and immunostaining (Figures $5 \mathrm{f}$ and g). SIN increased the frequency of Treg cells and decreased the frequency of Th17 cells, which was consistent with our previous findings in rat CIA. ${ }^{2}$ Notably, the reciprocal regulatory effect of SIN on Th17 and Treg cells was almost completely reversed by RES treatment, indicating that SIN might recover Th17/Treg balance in an AhR-dependent manner. 
a Control $\operatorname{SIN}(0.1 \mathrm{mM})$ $\operatorname{SIN}(0.3 \mathrm{mM})$ SIN (1 mM)
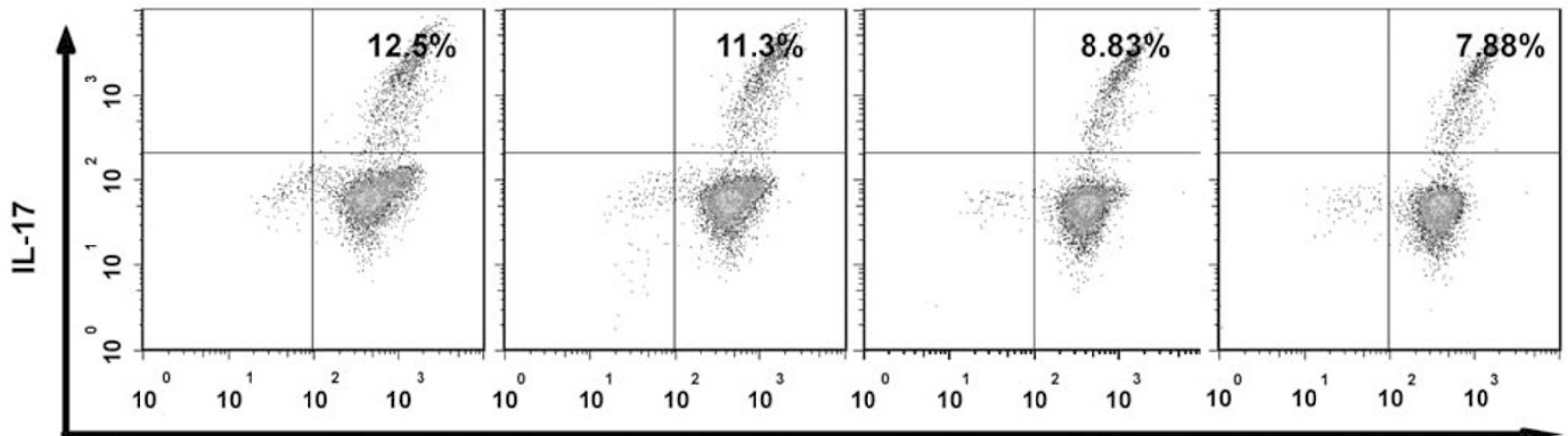

CD4

b

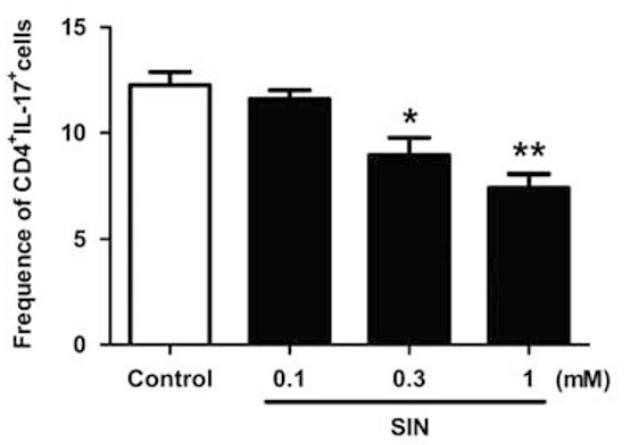

C

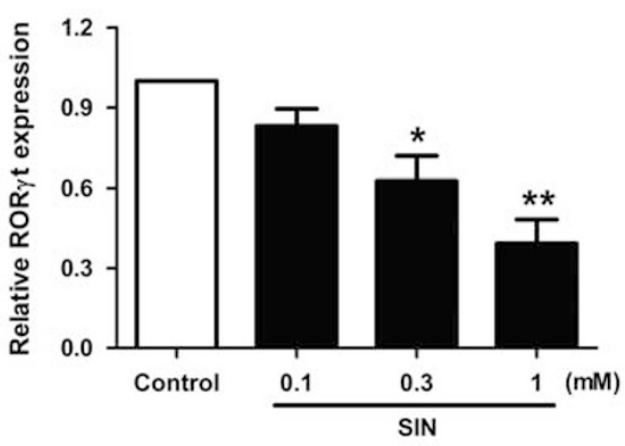

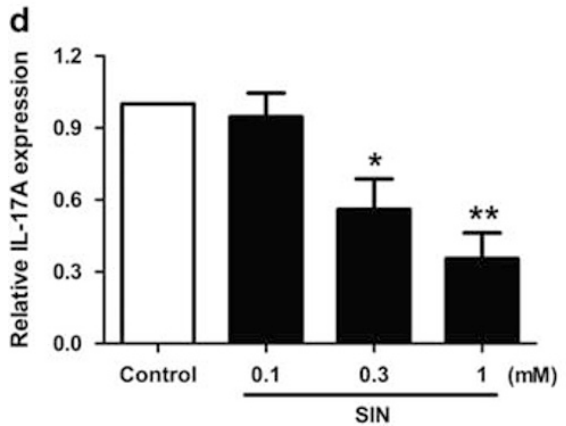
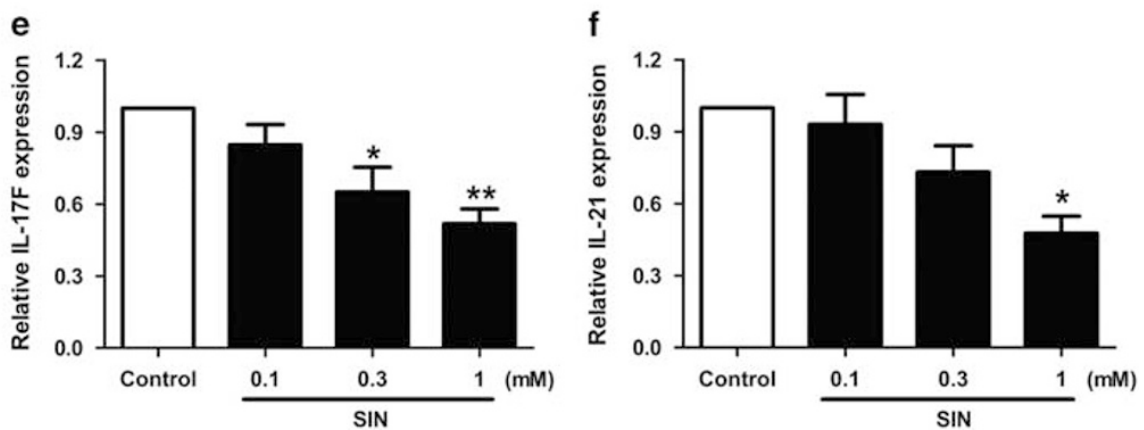

Figure 2 Sinomenine (SIN) decreased Th17 cell differentiation in vitro. (a,b) Frequency of IL- CD4 $17 \mathrm{~A}^{+}$cells was analyzed by flow cytometry. (c-f) Expressions of RORyt, IL-17A, IL-17 F, and IL-21 mRNA were analyzed by qPCR. Experiments were conducted three times, and data were expressed as means \pm s.e.m., $n=3$. ${ }^{*} P<0.05,{ }^{*} P<0.01$ vs control. qPCR, quantitative real-time $P C R$.

\section{SIN Reinforced the Anti-Arthritic Effect of Treg Cells}

$\mathrm{CD} 4{ }^{+} \mathrm{CD} 25^{+}$Treg cells isolated from the MLNs of SIN-treated and Model mice were transferred into recipient mice to clarify the effect of SIN on the activity of Treg cells. Adoptive transfer of SIN-Treg resulted in a more significant reduction of arthritis index in recipient mice compared with the mice in the Model-Treg group (Figure 5h). The joints from the recipient mice that received SIN-Treg exhibited a lower degree of inflammation and cartilage damage than those that received Model-Treg (Figures 5i and $\mathrm{j}$ ). Moreover, SIN-Treg reduced the serum levels of IL-17 and elevated the levels of IL-10 in recipient mice (Figure 5k). Mice that received SIN-Treg showed fewer Th17 cells and more Treg cells distribution in MLNs (Figures $5 \mathrm{l}$ and $\mathrm{m}$ ). The above results indicated that SIN strengthened the inhibitory effect of Treg cells on inflammatory arthritis.

\section{An AhR Antagonist Counteracted SIN-Mediated Alleviation of Mouse CIA}

Experimental arthritis was induced in male DBA1/J mice using CII in CFA, followed by a booster injection with CII in IFA. On day 26, several arthritic symptoms appeared and the indicated treatments started. After two weeks of treatment, mice in the model group developed arthritis rapidly, showing prominent symptoms such as paw swelling, erythema, and joint rigidity. SIN $(120 \mathrm{mg} / \mathrm{kg})$ yielded a marked decrease in arthritis index and paw swelling. RES $(20 \mathrm{mg} / \mathrm{kg})$ alone 
a
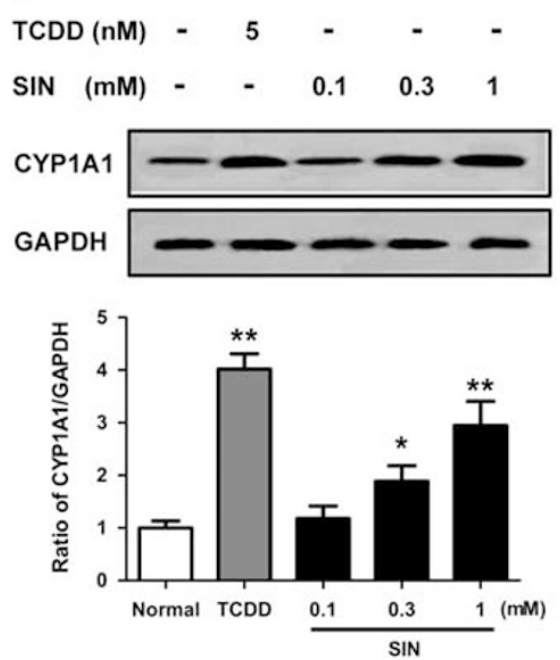

b

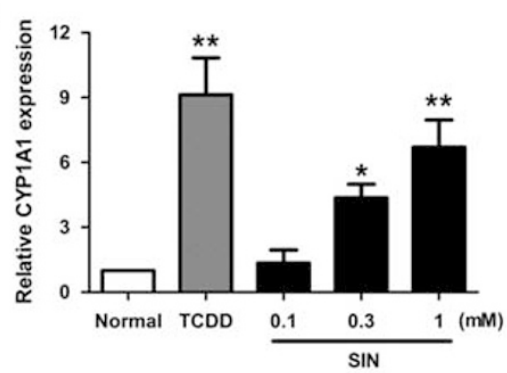

C

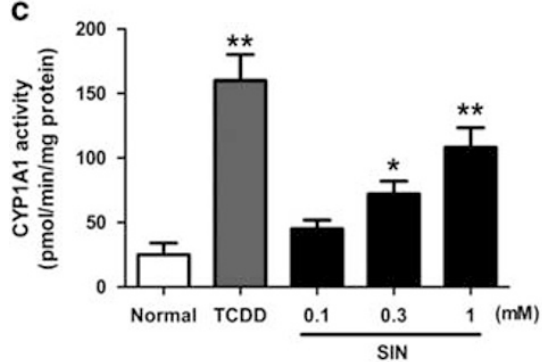

d
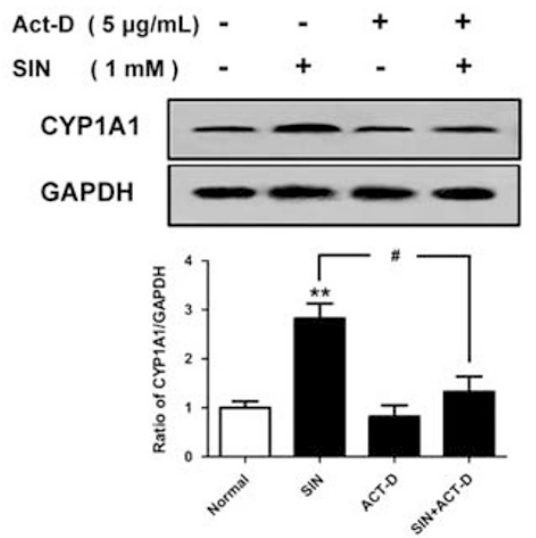

e

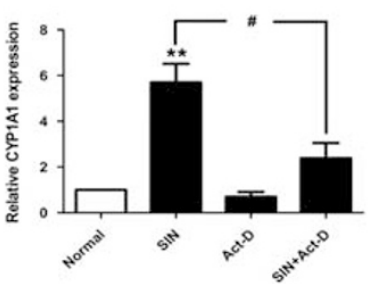

$\mathbf{f}$
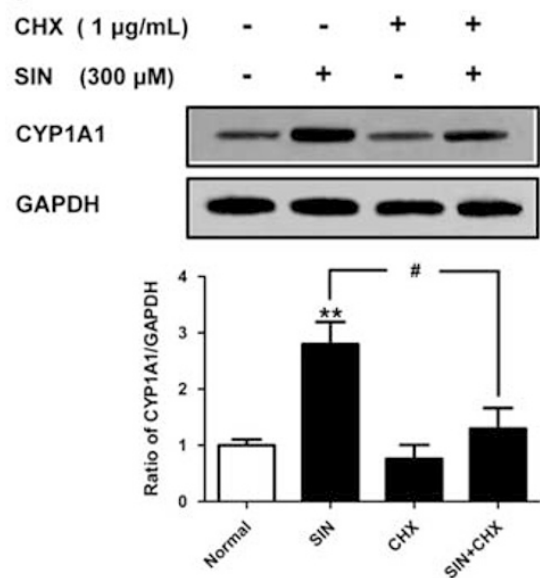

g
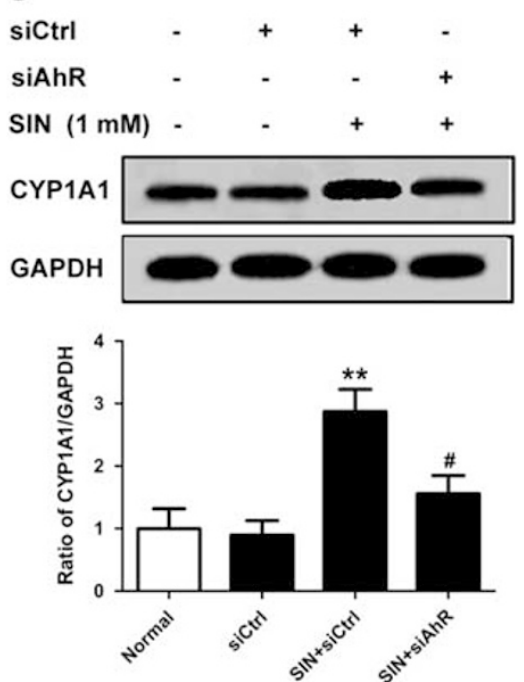

h
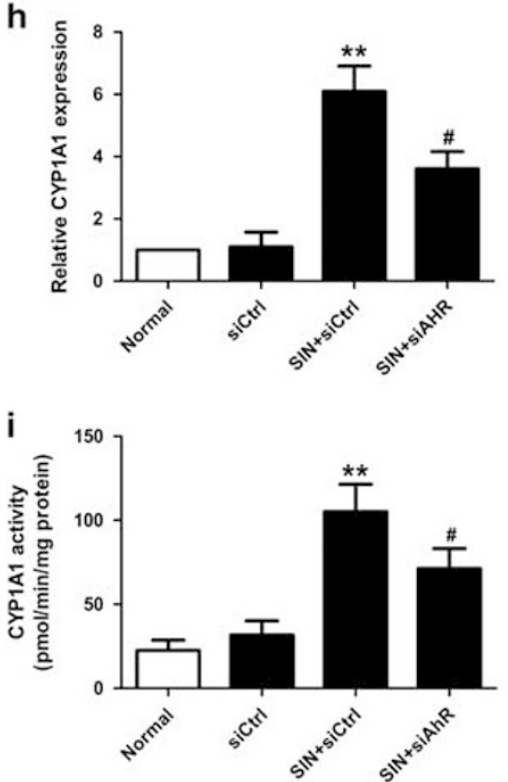

Figure 3 Sinomenine (SIN)-mediated CYP1A1 induction was dependent on AhR. (a-c) Lymphocytes were treated with various concentrations of SIN $(0.1,0.3$, and $1 \mathrm{mM})$. Protein and mRNA levels were analyzed by western blot and qPCR, and CYP1A1 activity was analyzed by ELISA. (d,e) Protein and mRNA levels of CYP1A1 were analyzed when cells were treated with vehicle or SIN (1 mM) with or without Act-D. (f) Protein level of CYP1A1 was analyzed when cells were treated with vehicle or SIN $(1 \mathrm{mM})$ with or without CHX. TCDD was used as an AhR agonist. Experiments were conducted three times, and data were expressed as means \pm s.e.m., ${ }^{*} P<0.05,{ }^{* *} P<0.01$ vs SINmal; ${ }^{\#} P<0.05$ vs SIN. (g-i) Lymphocytes, transduced with siCtrl or siAhR, was treated with vehicle or SIN (1M) for $24 \mathrm{~h}$ before assay. Protein and mRNA levels were analyzed by western blot and qPCR, and CYP1A1 activity was analyzed by ELISA. Experiments were conducted three times, and data were expressed as means \pm s.e.m., ${ }^{*} P<0.01$ vs siCtrl; ${ }^{\#} P<0.05$ vs siCtrl+SIN. AhR, aryl hydrocarbon receptor; CHX, cycloheximide; TCDD, 2,3,7,8-tetrachlorodibenzo-p-dioxin; qPCR, quantitative real-time PCR.

showed little effect on arthritis symptoms, but it markedly antagonized the anti-arthritic effect of SIN (Figures $6 a$ and $b$ ).

Histological analysis of inflamed hind paws showed high scores for inflammation $(8.35 \pm 0.49)$ and bone erosion score $(3.90 \pm 1.78)$ in the mice of the model group (Figures $6 \mathrm{c}$ and d). SIN, at a dose of $120 \mathrm{mg} / \mathrm{kg}$, reduced the inflammation score and bone erosion score to $5.78 \pm 0.56$ and $1.90 \pm 0.33$, respectively. However, RES mostly reversed the ameliorative effect of SIN on the pathological changes $(7.73 \pm 0.21$ and $2.85 \pm 0.57$, respectively).

In addition, SIN $(120 \mathrm{mg} / \mathrm{kg})$ markedly lowered the levels of total IgG and IgG2a in the sera, which could be largely counteracted by RES (Figure 6e). SIN treatment resulted in a marked depression of IL- $1 \beta$, TNF- $\alpha$, IL- 6 , and IL-17 levels, but a moderate promotion of IL-10 level, which was also markedly antagonized by RES (Figures $6 \mathrm{f}$ and $\mathrm{g}$ ). 
a

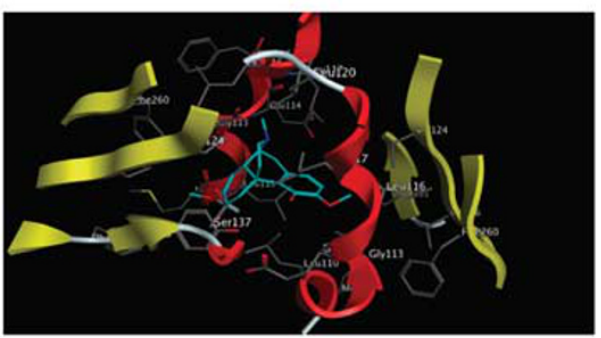

b

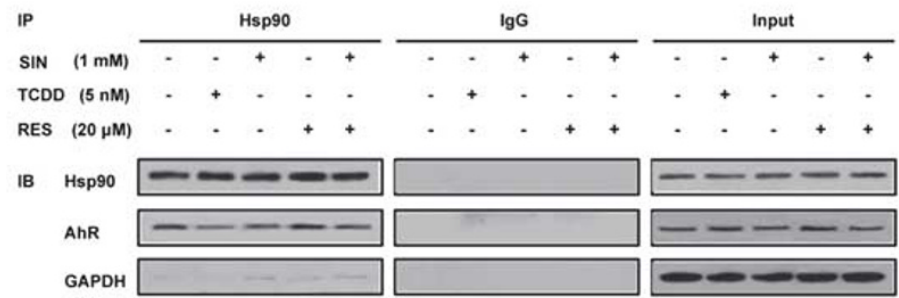

c
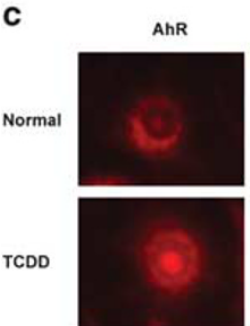

$\operatorname{SIN}$
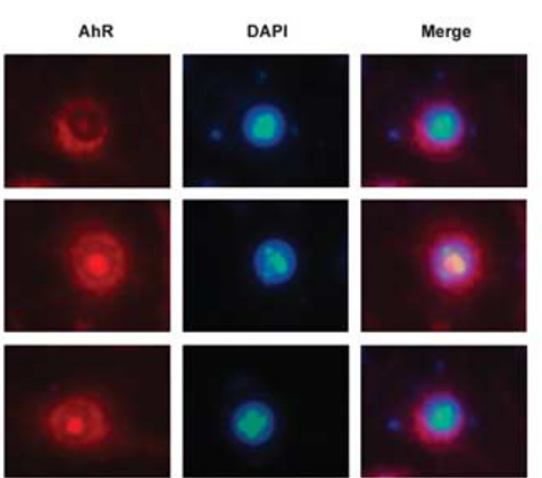

d
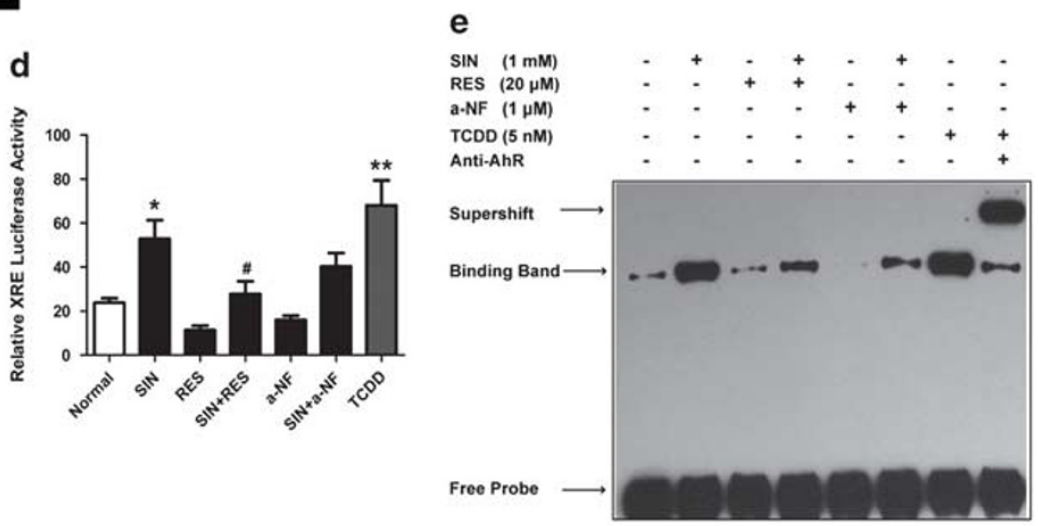

Figure 4 Sinomenine (SIN) activated AhR. (a) Molecular docking of SIN in the homology model of the AhR ligand-binding domain. (b) Protein samples from mesenteric lymph nodes were incubated with anti-Hsp90 or control $\lg G$ antibody overnight at $4{ }^{\circ} \mathrm{C}$, and resolved by SDS-PAGE and transferred to nitrocellulose membrane. Hsp90 and AhR in the immunoprecipitate were visualized by the respective antibodies. (c) Lymphocytes were treated with SIN $(1 \mathrm{mM})$ or TCDD ( $5 \mathrm{nM})$ for $3 \mathrm{~h}$. Cells were fixed and subjected to immunocytochemical staining using an AhR antibody (red, left column), and the images were superimposed with DAPI-stained images (blue, middle column); merged images (right column). Nuclear translocation of AhR was observed. This figure was representative of three independent experiments. (d) Lymphocytes were transfected with the XRE-Luc construct and then subjected to indicated treatments for $18 \mathrm{~h}$. SIN-induced XRE promoter activity was assayed by luciferase activity. (e) Lymphocytes were subjected to various treatments for $3 \mathrm{~h}$. XRE-AhR binding activity was measured using an electrophoretic mobility shift assay. The arrow indicates the AhR-XRE complex or supershift. AhR agonist TCDD and antagonists (resveratrol (RES), $a$-naphthoflavone ( $a$-NF)) were used. Experiments were conducted three times, and data were expressed as means \pm s.e.m., ${ }^{*} P<0.05,{ }^{* *} P<0.01$ vs normal; ${ }^{*} P<0.05$ vs SIN. AhR, aryl hydrocarbon receptor; TCDD, 2,3,7,8tetrachlorodibenzo-p-dioxin.

\section{DISCUSSION}

SIN has been used for the treatment of RA for several decades in China. The satisfactory therapeutic efficacy and fewer side effects of SIN in patients compared with the other treatments have been confirmed in open clinical trials.22,23 Earlier studies of SIN were focused on its anti-inflammatory effect. ${ }^{24}$ Recently, we investigated the immunomodulatory effect of SIN in rat CIA, an animal model of RA whose development is dependent on the participation of Th17 and Treg cells. ${ }^{2}$ Treatment of CII-immunized rats with SIN resulted in a dose-dependent inhibition of arthritis severity through the recirculation of lymphocytes from the gut to the inflamed joint. ${ }^{2}$ The present study was designed to investigate how SIN affects the differentiation and function of these cells. In vitro, SIN increased the differentiation of Treg cells, and decreased the differentiation of Th17 cells. Moreover, the Treg cells induced by SIN were shown to be more effective in regulation of Teff cells, which were manifested by up-regulation of a proliferation suppressive effect, increase of apoptosis induction, and inhibition of Th1 or Th17 differentiation. Treg cells were shown to play a central role in the SIN-mediated inhibition of arthritis. However, the way by which SIN participates in the induction of Treg cells remained unknown.

AhR is a ligand-activated transcription factor that belongs to the bHLH-PAS protein family, and is expressed by a vast majority of cells. ${ }^{25,26}$ The activation of AhR has recently been proven to be important in immune regulation. ${ }^{27,28}$ In natural products, isoquinoline alkaloid family has been recognized as important repertoires for $A h R$ ligand discovery. For example, berberine could activate $A h R$ signal pathway with a low toxicological potential. ${ }^{29}$ Either protopine or allocryptopine was able to induce the expression of CYP1A1 (downstream transcription factor of $A h R$ ) by a way associated with mild or negligible activation of $A h R .^{30}$ Other categories of alkaloid compounds, including arecoline, ${ }^{31}$ rutacarpine, ${ }^{32}$ and harmine, ${ }^{33}$ also manifested activation on AhR. Thus, SIN was more than likely to induce Treg cells and consequently inhibit arthritis through the regulation of $A h R$.

In the present study, SIN was shown to increase CYP1A1 expression at protein and mRNA levels in a concentrationdependent manner, and markedly promote CYP1A1 activity. Moreover, the increase of CYP1A1 expression induced by SIN was dependent on de novo RNA synthesis and protein 

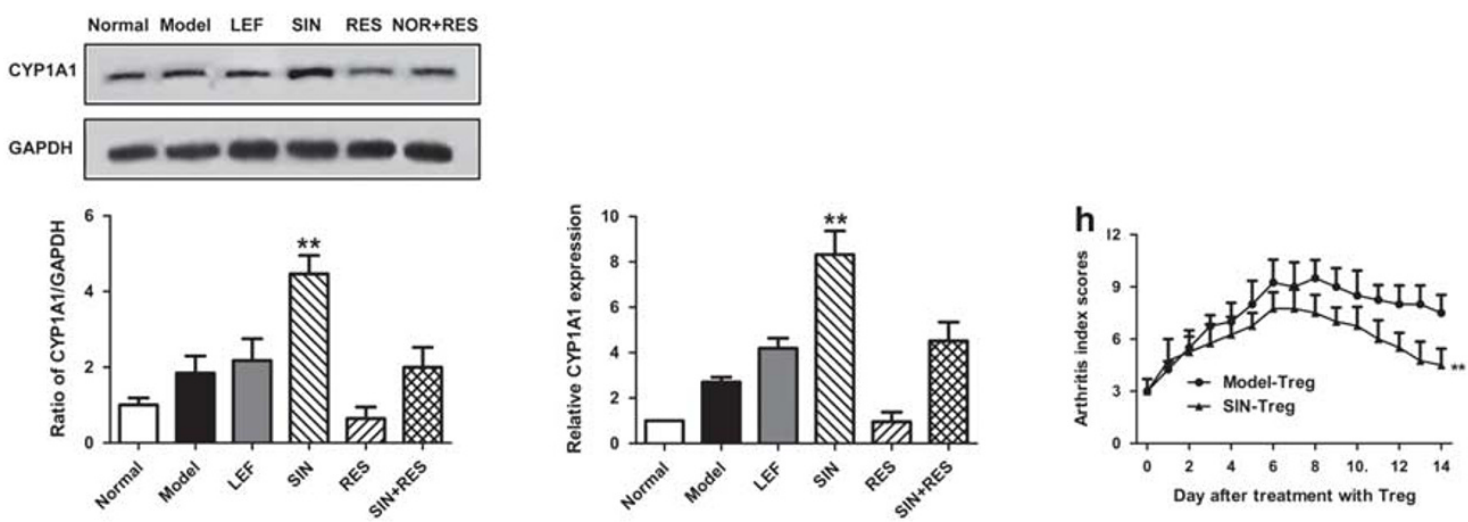

b
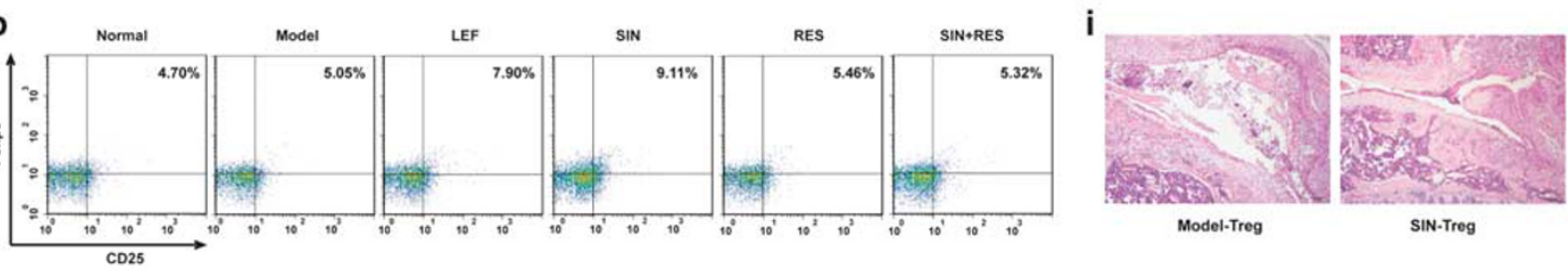

C
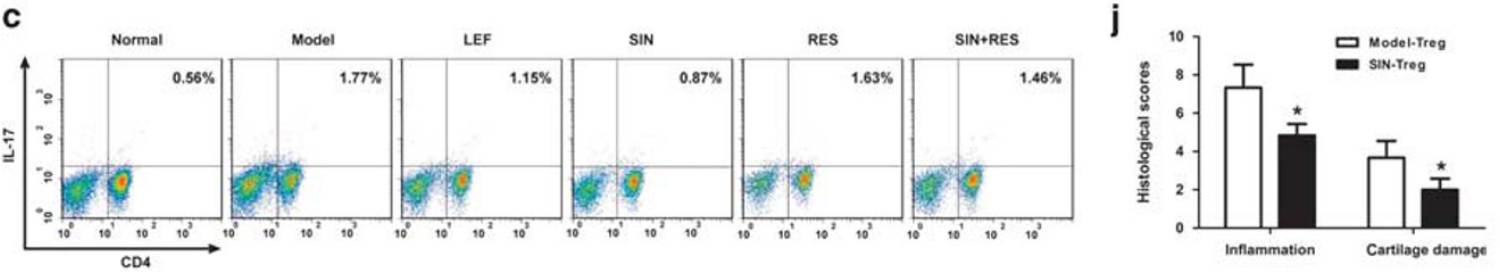

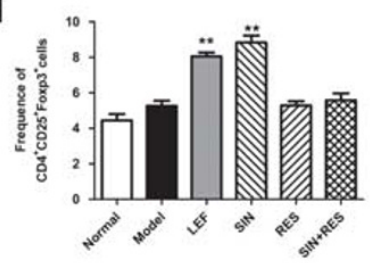

f
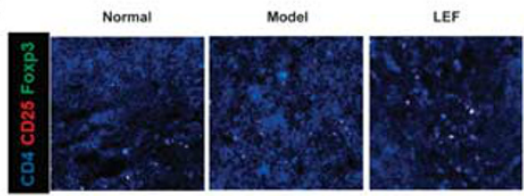

g

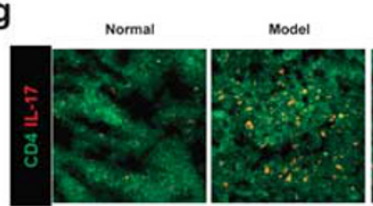

e

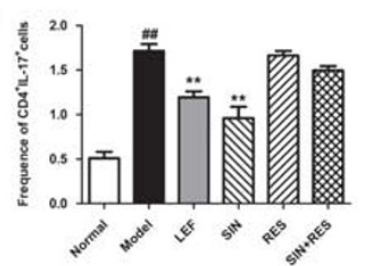

$\sin$
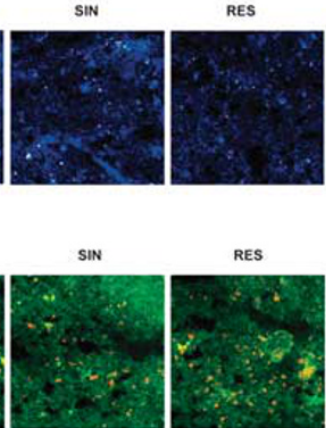

SIN+RES

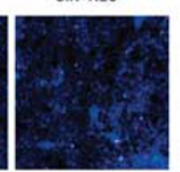

SIN+RES

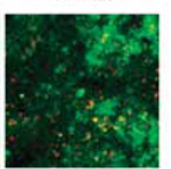

k

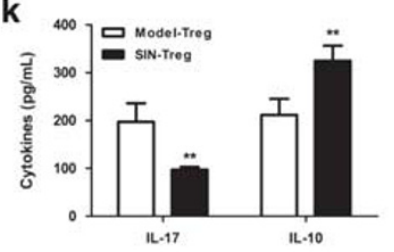

I

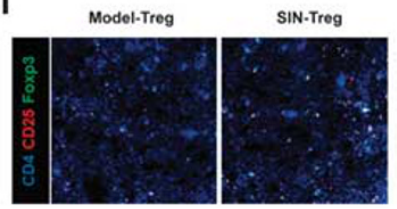

m

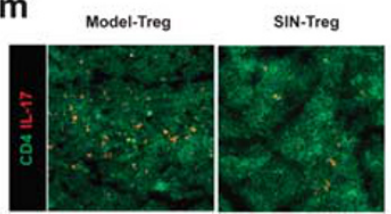

Figure 5 AhR antagonist abolished SIN-mediated regulation in Th17/Treg balance in mouse CIA. (a) Protein and mRNA levels of CYP1A1 in mesenteric lymph nodes (MLNs) were evaluated by western blot and GPCR, respectively. (b-e) Lymphocytes from MLNs was stained with antibodies against CD4/ CD25/Foxp3 and CD4/IL-17. Frequency of $\mathrm{CD}_{2} 5^{+} \mathrm{Foxp}^{+}$cells in $\mathrm{CD} 4^{+}$cells and frequency of IL- $17 \mathrm{~A}^{+}$cells in $\mathrm{CD} 4^{+}$cells were analyzed by flow cytometry. $(\mathbf{f}, \mathbf{g})$ Confocal microscopy was used to visually enumerate each of cell subsets (Th17, Treg) in MLNs after specific antibodies binding. Resveratrol (RES) was used as an AhR antagonist. Results were the mean \pm s.e.m., $n=8$. ${ }^{*} P<0.05,{ }^{* *} P<0.01$ vs Model; ${ }^{\# \#} P<0.01$ vs normal. (h) CD4 ${ }^{+} \mathrm{CD} 25^{+} \mathrm{T}-\mathrm{cell}$ s isolated on SIN- or vehicle-treated CIA mice were adoptively transferred into recipient mice three times. Arthritis index scores were evaluated. (i,j) Joint tissue sections were assessed for histologic features by hematoxylin and eosin (H\&E), and histologic scores were determined. (k) Levels of IL-17 and IL-10 in mouse sera were determined two weeks after arthritic symptom appeared. (I, $\mathbf{m})$ Confocal microscopy was used to visually enumerate each of cell subsets (Th17, Treg) in MLNs from recipient mice. Results were means \pm s.e.m., $n=5$. ${ }^{*} P<0.05,{ }^{*} P<0.01$ vs Model-Treg. AhR, aryl hydrocarbon receptor; SIN, sinomenine; CIA, collagen-induced arthritis; GPCR, Quantitative real-time PCR. 
a

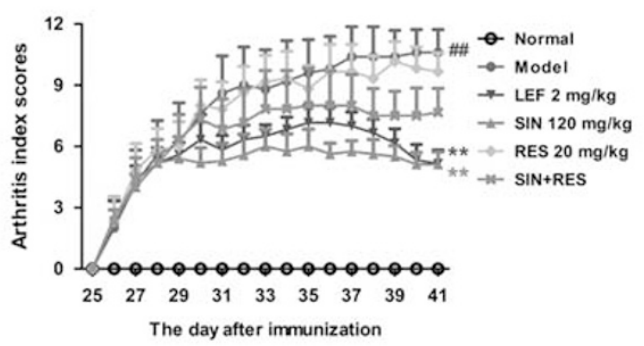

c

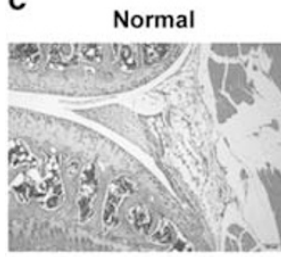

$\operatorname{SIN}$

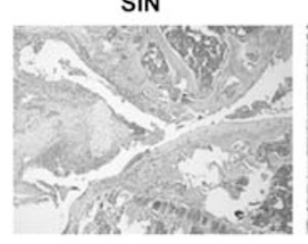

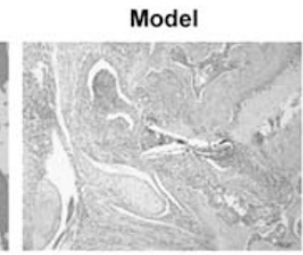

RES

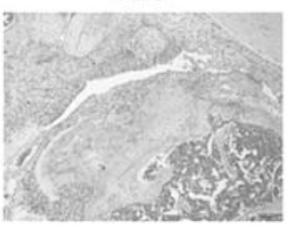

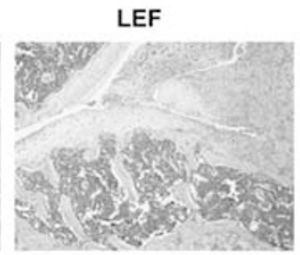

SIN+RES

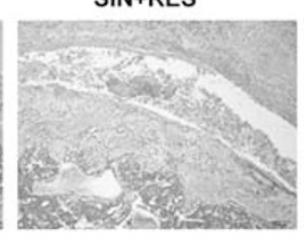

d
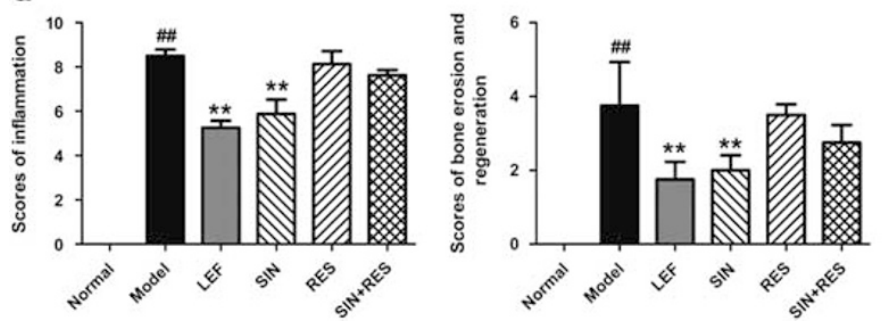

b

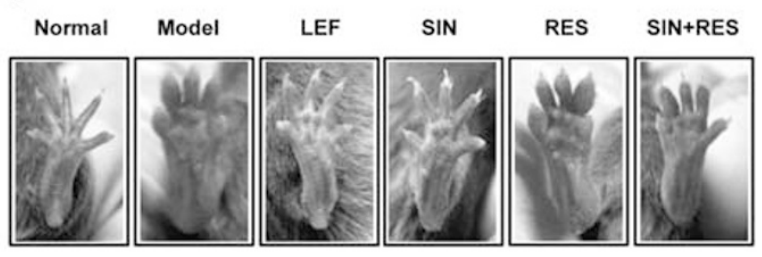

e
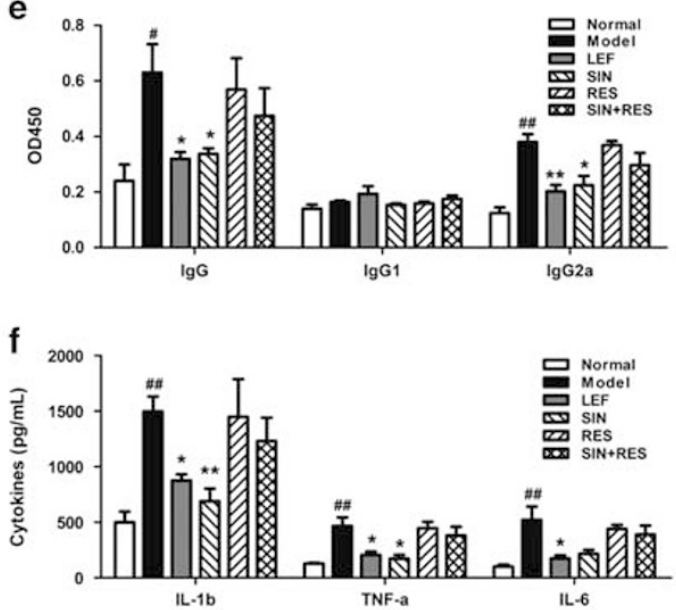

g

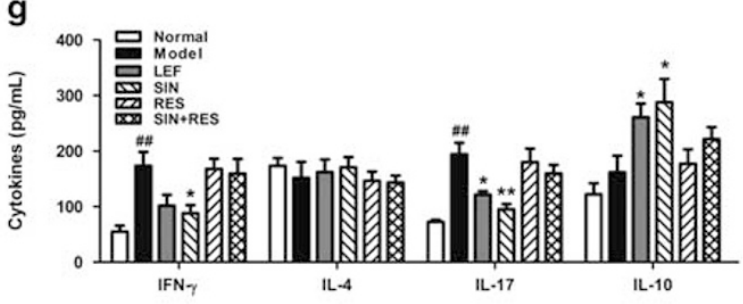

Figure 6 AhR antagonist abolished SIN-mediated alleviation in mouse CIA. (a) Arthritis index scores were evaluated in each group. (b) The paws swelling was shown representatively. (c,d) Histologic examinations of the joints from mice in each group were performed using H\&E. Histologic grades were evaluated according to inflammatory cell infiltration, synovial hyperplasia and congestion, fibroustissue hyperplasia, and bone erosion and regeneration. The histological scores of all groups were summarized. (e) Sera levels of anti-Cll antibodies (IgG, IgG1, and IgG2a) were measured using ELISA kits. (f) Serum levels of proinflammatory factors (IL-1 $\beta$, TNF- $a$, and IL-6) were measured using ELISA kits. (g) Serum levels of Th1/Th2/Th17/Tregrelated cytokines (IFN- $\gamma$, IL-4, IL-17, and IL-10) were measured using ELISA kits. Resveratrol (RES) was used as an AhR antagonist. Results were means \pm s.e.m., $n=8$. ${ }^{*} P<0.05,{ }^{* *} P<0.01$ vs Model; ${ }^{\#} P<0.05,{ }^{\# \#} P<0.01$ vs normal. AhR, aryl hydrocarbon receptor; SIN, sinomenine; CIA, collagen-induced arthritis; $\mathrm{H} \& \mathrm{E}$, hematoxylin and eosin.

synthesis. By contrast, siAhR transfection almost entirely diminished SIN-mediated CYP1A1 induction, indicating that the induction effect of SIN was mediated by $A h R$. It is well known that the action of $A h R$ involves a multi-step, ligandinduced signal transduction process. The ligand binds to $A h R$ and triggers the $A h R / H s p 90$ complex dissociation. Activated $A h R$ translocates into the nucleus, dimerizes with $A R N T$, binds to specific enhancer sequences (XRE), and activates the transcription of target genes. ${ }^{15}$ In the present study, the data obtained from molecular docking showed that SIN could stably associate with $A h R$. Furthermore, SIN promoted the dissociation of $A h R / H s p 90$ complex, facilitated the nuclear translocation of $A h R$, and increased XRE-dependent luciferase reporter gene expression. EMSA assay demonstrated that SIN was able to facilitate the binding of $A h R$ to XRE. These findings indicated that SIN is an $A h R$ ligand. As several isoquinoline alkaloids can activate $A h R,{ }^{10,11}$ further studies on the structure-activity relationship should be valuable.

In the final part of this study, an $A h R$ antagonist was used to clarify the AhR activation effect of SIN in vivo. We noted that the immunomodulatory effect and anti-arthritic effect of SIN manifested in an AhR-dependent manner. An adoptive transfer of Treg cells from SIN-treated mice showed more obvious improvement of arthritis symptoms in recipient mice, which indicates that SIN prompted the function of Treg cells. In combination with our previous findings in rat CIA, we can conclude that Treg cells are the key effectors for amelioration of RA after SIN treatment. 
In summary, we report that SIN functions as an AhR agonist, induces Treg cell generation and function, and thereby alleviates arthritis. At present, SIN is not considered as the first line of defense drug for the treatment of RA. Given our findings that this drug potentiates Treg activity, a means of site-or cellspecific delivery of this drug to Treg cells may render its benefit in the treatment of autoimmunity diseases. Such an approach would likely decrease the amount of drug required for treatment as well as improve the overall efficacy of SIN.

Supplementary Information accompanies the paper on the Laboratory Investigation website (http://www.laboratoryinvestigation.org)

\section{ACKNOWLEDGMENTS}

This work was supported by the National Natural Science Foundation of China (No. 81373426) and the Priority Academic Program Development of Jiangsu Higher Education Institutions.

\section{DISCLOSURE/CONFLICT OF INTEREST}

The authors declare no conflict of interest.

1. Xu M, Liu L, Qi C, et al. Sinomenine versus NSAIDs for the treatment of rheumatoid arthritis: a systematic review and meta-analysis. Planta Med 2008;74:1423-1429.

2. Tong B, Yu J, Wang T, et al. Sinomenine suppresses collagen-induced arthritis by reciprocal modulation of regulatory T cells and Th17 cells in gut-associated lymphoid tissues. Mol Immunol 2015;65:94-103.

3. Ema M, Sogawa K, Watanabe $N$, et al. cDNA cloning and structure of mouse putative Ah receptor. Biochem Biophys Res Commun 1992;184: 246-253.

4. Hankinson O. The aryl hydrocarbon receptor complex. Annu Rev Pharmacol Toxicol 1995;35:307-340.

5. Lee JS, Cella M, McDonald KG, et al. AHR drives the development of gut ILC22 cells and postnatal lymphoid tissues via pathways dependent on and independent of Notch. Nat Immunol 2011;13:144-151.

6. Li Y, Innocentin S, Withers DR, et al. Exogenous stimuli maintain intraepithelial lymphocytes via aryl hydrocarbon receptor activation. Cell 2011;147:629-640.

7. Zelante T, lannitti RG, Cunha C, et al. Tryptophan catabolites from microbiota engage aryl hydrocarbon receptor and balance mucosal reactivity via interleukin-22. Immunity 2013;39:372-385.

8. Zhou L. AHR function in lymphocytes: emerging concepts. Trends Immunol 2016;37:17-31.

9. Qiu J, Zhou L. Aryl hydrocarbon receptor promotes RORyt ${ }^{+}$group 3 ILCS and controls intestinal immunity and inflammation. Semin Immunopathol 2013;35:657-670.

10. Tong B, Yuan X, Dou Y, et al. Norisoboldine, an isoquinoline alkaloid, acts as an aryl hydrocarbon receptor ligand to induce intestinal Treg cells and thereby attenuate arthritis. Int J Biochem Cell Biol 2016;75: 63-73.

11. Yuan $X$, Tong B, Dou $Y$, et al. Tetrandrine ameliorates collagen-induced arthritis in mice by restoring the balance between Th17 and Treg cells via the aryl hydrocarbon receptor. Biochem Pharmacol 2016;101: 87-99.

12. Park JS, Lee J, Lim MA, et al. AK2-STAT3 blockade by AG490 suppresses autoimmune arthritis in mice via reciprocal regulation of regulatory T Cells and Th17 cells. J Immunol 2014;192:4417-4424.
13. Tong B, Dou Y, Wang $T$, et al. Norisoboldine ameliorates collageninduced arthritis through regulating the balance between Th17 and regulatory $\mathrm{T}$ cells in gut-associated lymphoid tissues. Toxicol Appl Pharmacol 2015;282:90-99.

14. Lu Q, Tong B, Luo Y, et al. Norisoboldine suppresses VEGF-induced endothelial cell migration via the cAMP-PKA-NF-KB/Notch1 pathway. PLoS One 2013;8:e81220.

15. Gharavi N, El-Kadi AO. tert-Butylhydroquinone is a novel aryl hydrocarbon receptor ligand. Drug Metab Dispos 2005;33:365-372.

16. Kong $\mathrm{N}$, Lan $\mathrm{Q}$, Chen $\mathrm{M}$, et al. Antigen-specific transforming growth factor beta-induced Treg cells, but not natural Treg cells, ameliorate autoimmune arthritis in mice by shifting the Th17/Treg cell balance from Th17 predominance to Treg cell predominance. Arthritis Rheumatol 2012;64:2548-2558.

17. Tong B, Wan B, Wei Z, et al. Role of cathepsin B in regulating migration and invasion of fibroblast-like synoviocytes into inflamed tissue from patients with rheumatoid arthritis. Clin Exp Immunol 2014;177:586-597.

18. Park JS, Kwok SK, Lim MA, et al. STA-21, a promising STAT-3 inhibitor that reciprocally regulates Th17 and Treg cells, linhibits osteoclastogenesis in mice and humans and alleviates autoimmune inflammation in an experimental model of rheumatoid arthritis. Arthritis Rheumatol 2014;66:918-929.

19. Gandhi R, Kumar D, Burns EJ, et al. Activation of the aryl hydrocarbon receptor induces human type 1 regulatory $T$ cell-like and Foxp3(+) regulatory T cells. Nat Immunol 2010;11:846-853.

20. Punj S, Kopparapu P, Jang HS, et al. Benzimidazoisoquinolines: a new class of rapidly metabolized aryl hydrocarbon receptor (AhR) ligands that induce AhR-dependent Tregs and prevent murine graft-versushost disease. PLoS One 2014;19:e88726.

21. Wang $\mathrm{HK}$, Yeh $\mathrm{CH}$, Iwamoto $\mathrm{T}$, et al. Dietary flavonoid naringenin induces regulatory $\mathrm{T}$ cells via an aryl hydrocarbon receptor mediated pathway. J Agric Food Chem 2012;60:2171-2178.

22. Huang G, Li J, Huang $Y$, et al. The clinical study on sinomenine for 100 patients with rheumatoid arthritis. J Emerg Tradit Chin Med 2007;16: 416-421.

23. Shi PM, Ma ZX, Zhang WZ. Therapeutic efficacy of sinomenine on 60 rheumatoid arthritis cases. Xin Yi Xue 1985;3:292-293.

24. Hua HR, Chen XP. Study on mechanisms of sinomenine on analgesic and anti-inflammatory actions. J Xian Med Univ 1989;4:346-349.

25. Tian Y. Ah receptor and NF-kappaB interplay on the stage of epigenome. Biochem Pharmacol 2009;77:670-680.

26. Hahn ME. Aryl hydrocarbon receptors: diversity and evolution. Chem Biol Interact 2002;141:131-160.

27. Esser C, Rannug A, Stockinger B. The aryl hydrocarbon receptor in immunity. Trends Immunol 2009;30:447-454.

28. Stevens EA, Mezrich JD, Bradfield CA. The aryl hydrocarbon receptor: a perspective on potential roles in the immune system. Immunology 2009;127:299-311.

29. Vrzal R, Zdarilova A, Ulrichova J, et al. Activation of the aryl hydrocarbon receptor by berberine in HepG2 and H4IIE cells: Biphasic effect on CYP1A1. Biochem Pharmacol 2005;70:925-936.

30. Vrba J, Vrublova E, Modriansky $M$, et al. Protopine and allocryptopine increase mRNA levels of cytochromes P450 1A in human hepatocytes and HepG2 cells independently of AhR. Toxicol Lett 2011;203:135-141.

31. Chang EE, Miao ZF, Lee WJ, et al. Arecoline inhibits the 2,3,7,8tetrachlorodibenzo-p-dioxin-induced cytochrome P450 1A1 activation in human hepatoma cells. J Hazard Mater 2007;146:356-361.

32. Han EH, Kim HG, Im JH, et al. Up-regulation of CYP1A1 by rutaecarpine isdependent on aryl hydrocarbon receptor and calcium. Toxicology 2009;266:38-47.

33. El-Gendy MA, El-Kadi AO. Harman induces CYP1A1 enzyme through an aryl hydrocarbon receptor mechanism. Toxicol Appl Pharmacol 2010;249:55-64. 